\title{
Experimental Investigation of Tensile Properties in a Glass/Epoxy Sample Manufactured by Vacuum Infusion, Vacuum Bag and Hand Layup Process
}

\author{
Amin Abbasi Talabari*, Mohammad Hossein Alaei, Hamid Reza Shalian \\ Center for Composite Materials, Malek Ashtar University, Tehran, 31559-77788, Iran
}

Corresponding Author Email: aminabbasi70@mut.ac.ir

https://doi.org/10.18280/rcma.290308

Received: 11 March 2019

Accepted: 29 May 2019

\section{Keywords:}

VIP, vacuum bag, hand layup, tensile strength, modulus, inter-laminar bonding, surface macroscopy

\begin{abstract}
In order to achieve a high-quality composite, a proper manufacturing technique should be used. Glass Fiber Reinforced Plastic (GFRP) structures are commonly manufactured using hand layup, vacuum bag and vacuum infusion process (VIP) which are cost effective techniques. This paper compares the tensile strength, modulus, inter-laminar bonding and surface macroscopy of GFRP composites made by hand layup, vacuum bag and VIP process. For this reason, at first GFRP sample were manufactured using these three methods and then tested for tensile properties. In the next step, these samples were modeled numerically and compared. The results show that the strength of the sample made by VIP process is $20 \%$ higher than the hand layup and $11 \%$ higher than vacuum bag sample. Also, the modulus of the sample achieved using VIP is $21 \%$ higher that hand layup and $15 \%$ higher than vacuum bag technique. By comparing the failure mechanism of the samples, it was observed that the inter-laminar bonding is highest in VIP and then vacuum bag and lastly hand layup due to a smaller number of voids. Lastly the numerical results showed to have a good agreement with the experimental results.
\end{abstract}

\section{INTRODUCTION}

Nowadays, composite materials have found a wide application in many industries due to their high specific properties. These materials compose of reinforcing agents and a compatible matrix in order to obtain the desired properties. In composites, unlike in alloys, the components do not merge completely, but however do act in concert [1]. The matrix material used in manufacturing of composites consists of polyester, phenolic, polyimide, and epoxy. Reinforcements used could be different grades of carbon, Kevlar and glass where fiberglass provides a significant advantage on the costto-performance basis [2-4].

They are many composite manufacturing techniques used today with each having their own advantages and disadvantages. Hand layup is the simplest and cheapest technique used today although the percentage of void is high in this process [5-7]. Vacuum bag almost has the advantages of hand layup but can produce parts with less number of voids [8]. Vacuum infusion process (VIP) has become very attractive in the recent years due to its ability to use cheap tools to build large parts.

VIP is a clean process that produces parts with high mechanical properties since fiber volume percentage could go up to $60 \%$ in this process. In addition, low operator interference increases the process repeatability in comparison with open-loop-like techniques [9-11].

There are few studies where the researchers have compared the properties of samples manufactured by different techniques. For example, Wisojodharmo et al. [12] compared the mechanical properties of the wind turbine blade made by VIP and Hand layup. The results of their research showed that composite materials made by VIP has better properties than the samples made by laminating method such that its modulus of elasticity was $40.36 \%$, tensile strength $42.54 \%$ and the compressive strength was $106.87 \%$ higher than the hand layup samples. Also, by using VIP, the weight of the sample was decreased by $38 \%$. Bhatangar [13] compared VIP and hand layup for manufacturing of a composite boat. The results from his experiments show that the bending strength of the test specimens manufactured via the VIP method is almost twice as the hand layup sample. Almost same result was reported by Yuhazri et al. [14] for Kenaf-polyester composites made with VIP and hand layup. Khalili et al. [15] investigated the compressive properties of a kevlar-glass/polyester sandwich composite with a balsa core. It was shown that using VIP, the compressive strength of the composite sandwich improves by $46 \%$.

In this paper, the tensile properties and inter laminar bonding of a glass/epoxy composite sample manufactured by vacuum infusion, vacuum bag and hand layup process has been compared.

\section{MATERIALS AND METHODS}

\subsection{Material}

2017 Epoxy supplied by Axson ltd. along with 2017 hardener was used as the matrix material. The specifications of the resin and hardeners are shown in Table 1. As for the reinforcement, E glass fabric having $400 \mathrm{gr} / \mathrm{m}^{2}$ supplied by AMP ltd. 
Table 1. Epoxy resin specification

\begin{tabular}{ccc}
\hline Property & Resin 2017 & Hardener 2017 \\
\hline Mix ratio by weight & $100 \mathrm{gr}$ & $30 \mathrm{gr}$ \\
Mixed viscosity at $25^{\circ}$ & & $700 \mathrm{gr} / \mathrm{cm} \cdot \mathrm{sec}$ \\
Flexural Modulus & & $3.700 \mathrm{MPa}$ \\
Flexural Strength & & $132 \mathrm{MPa}$ \\
\hline
\end{tabular}

\subsection{Sample manufacturing}

For manufacturing of the composite samples, a glass mold with $50 \mathrm{~cm}$ length and $40 \mathrm{~cm}$ width was used. For hand layup samples, after the preparation of the mold, 8 layers were applied one by one at the angels of $0 / 90$ until the required thickness of the sample was achieved. For vacuum bag samples, the procedure was same as hand layup after which the vacuum was placed around the mold and sealed. Finally, these samples were cured under vacuum. The manufacturing steps for VIP samples included applying the releasing agent to the glass mold, placing the peel ply layer and mesh infusion. The total number of fabric layers used was 8 in order to obtain the ASTM D3039 standard specimen thickness $(2.5 \mathrm{~mm})$. In the next step, the inlet and outlet resin transfer pipes were placed around the fabrics and finally the mold was sealed using a vacuumed bag. A resin trapper was used between the mold and the pump to absorb the extra resin through the outlet. When the setup was ready, the air inside the mold was evacuated by closing the inlet pipe after which the resin inlet valve was opened. In order to extract the extra resin and air bubbles inside the sample, after the complete feeling of the mold, the inlet line was closed while the vacuum pump continued to operate. After the samples were cured, they were taken out of the mold and cut according to the dimension of ASTM D3039 standard $(25 \mathrm{~cm} \times 2.5 \mathrm{~cm})$ for tensile testing. Figure 1(a), 1(b) and 1(c) show the manufacturing of the composite samples using the VIP, vacuum bag and hand layup respectively.

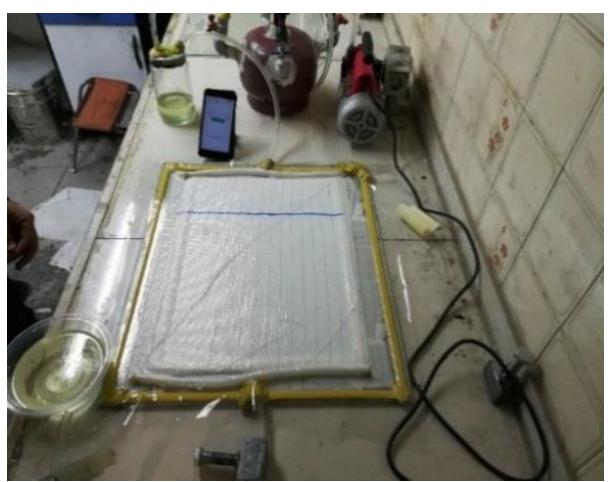

(a) Using VIP

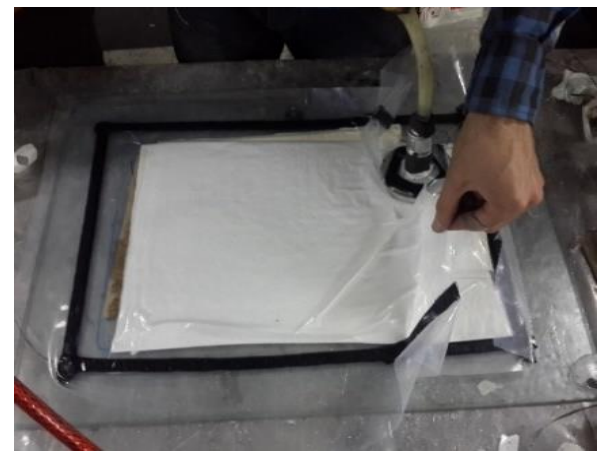

(b) Using vacuum bag

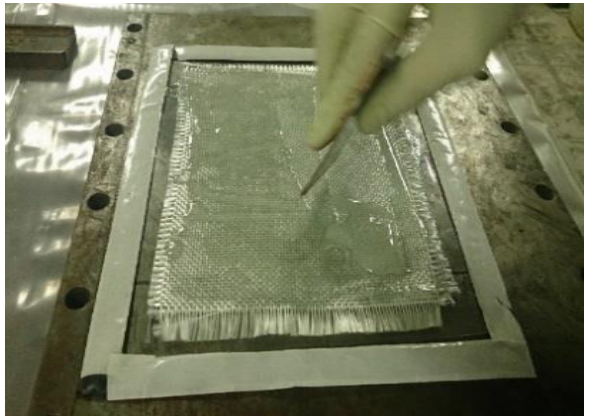

(c) Using hand layup

Figure 1. Manufacturing of the composite sample

The tabs used on both ends of the tensile samples were cut from the same sample and joined at the angel of $\pm 45^{\circ}$. For each of the manufacturing techniques, 5 samples were manufactured. Figure 2 shows the prepared tensile using the three methods.

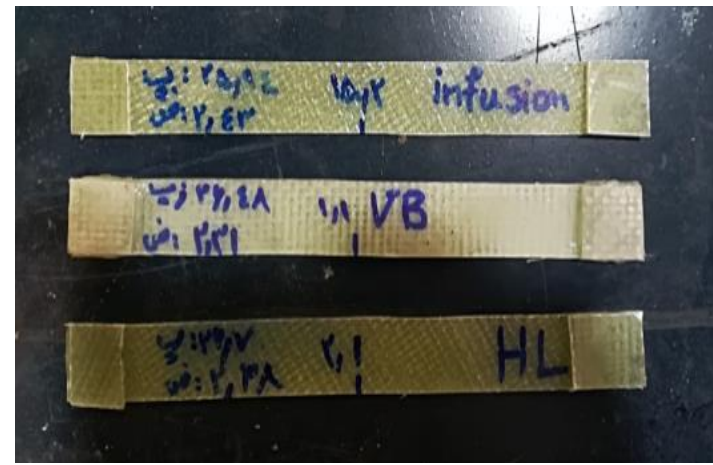

Note: upper - VIP; middle - vacuum bag; lower - hand layup

Figure 2. the prepared composite tensile samples by three techniques

\subsection{Characterization of the sample}

When the samples were ready, tensile testing was performed at the rate of $5 \mathrm{~mm} / \mathrm{min}$ according to ASTM D3039 standard [8] on Santam S150 tensile testing machine. In order to increase the accuracy during the testing, extensometer was attached to the specimens. Figure 3 shows the manufactured composite samples during the tensile testing.

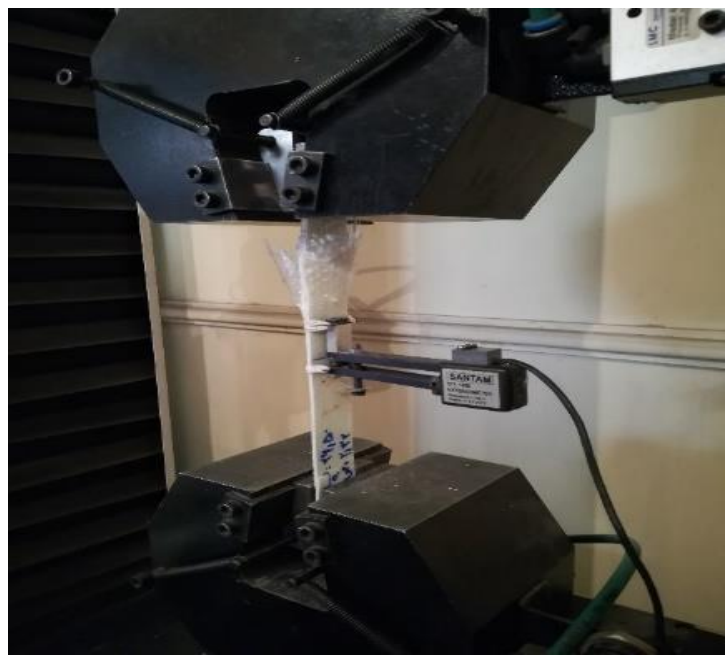

Figure 3. Samples tested 
Finally, in order to observe the micro structure and voids of the produced samples, optical microscope with 50x magnification was used.

\section{RESULT AND DISCUSSION}

The average tensile strength and modulus of the 5 samples made by hand layup, vacuum bag and VIP has been presented in Figure 4. As it can be observed, the strength of the sample made using the VIP is $11 \%$ higher than the vacuum bag and $20 \%$ higher than the hand layup process. Also, the modulus of VIP sample is $15 \%$ higher than the vacuum bag and $20 \%$ higher than the hand layup samples. The reason could be the higher volume fraction of the reinforcement and less number of voids in the VIP samples.

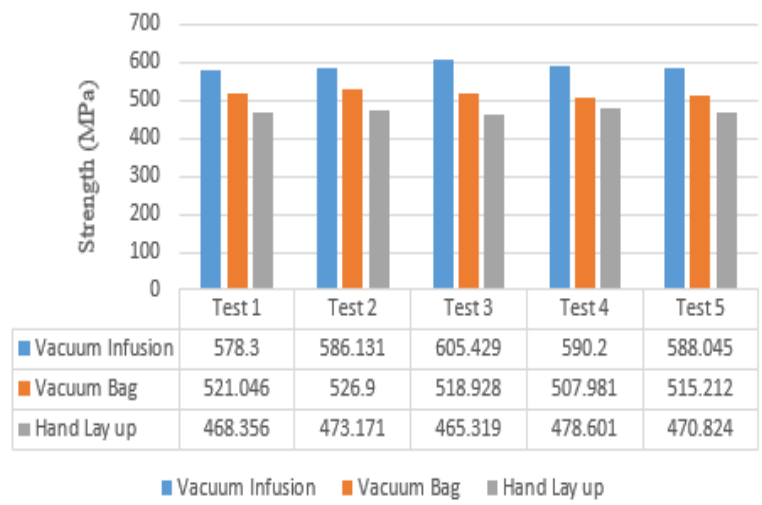

(a) Strength

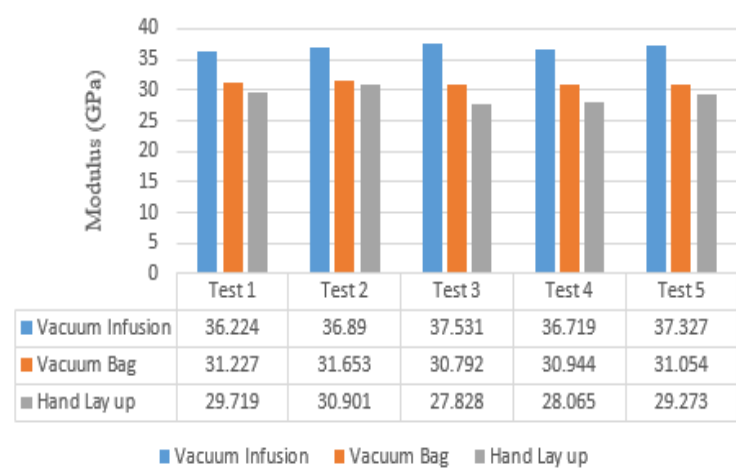

(b) Modulus

Figure 4. Comparison of samples tested by all three processes

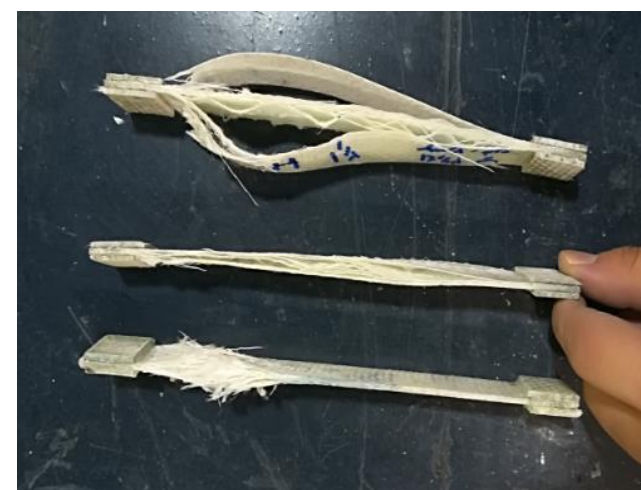

Note: upper - hand layup; middle - vacuum bag; lower - VIP

Figure 5. The failed tensile samples
Figure 5 shows the failed samples of hand layup, vacuum bag and VIP. It can be observed that the inter-laminar bonding is highest in the VIP sample since no layer delamination is observed on this sample unlike vacuum bag which has a slight delamination and hand layup with a very large area of delamination.

Figure 6 shows the images from optical microscope taken from the hand layup, vacuum bag and VIP sample. It can be observed that the VIP sample is free from void, since the layers are continuously soaked from extra resin, and the air bubbles are directed towards the outlet pipe. Comparing vacuum bag and hand layup, it is observed that hand layup has the highest amount of void since in vacuum bag process, some portion of the extra resin and void content is guided towards the top of the mold and into the bleeder layer.

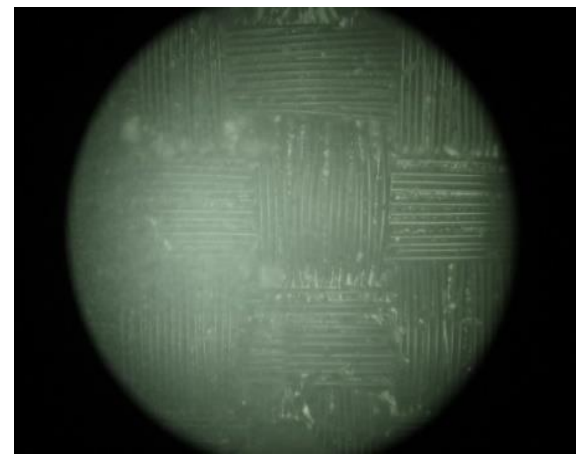

(a) Vacuum Infusion

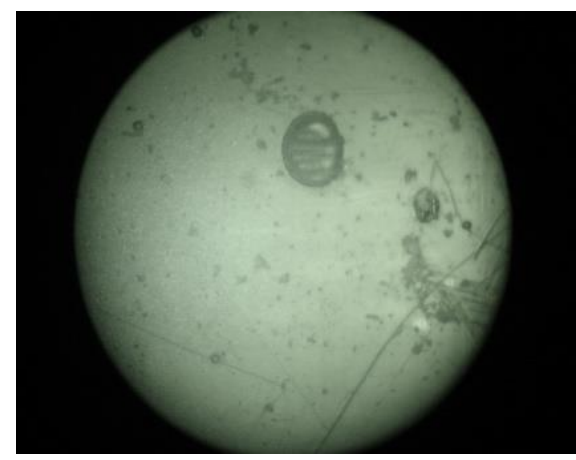

(b) Vacuum bag

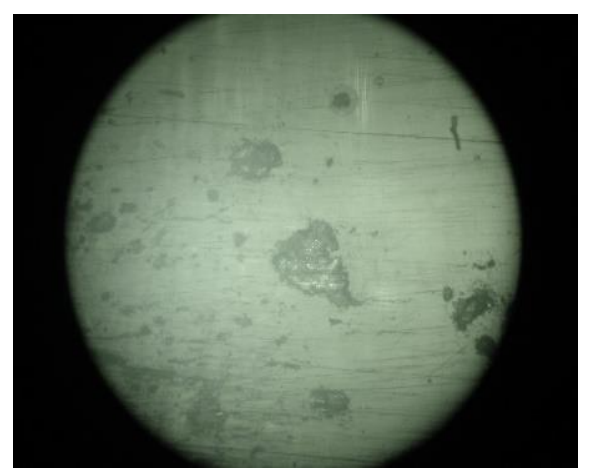

(c) Hand layup

Figure 6. Comparison of the microscopic surface of the samples made in three ways

\section{CONCLUSIONS}

In this study, the tensile as well as inter-laminar properties of GFRP composite made by the three processes of hand layup, vacuum bag and VIP was compared. 
It was observed that higher tensile strength could be achieved by VIP when compared with vacuum bag (11\% higher) and hand layup (20\% higher). The VIP sample had a modulus which was $15 \%$ higher than the vacuum bag and $20 \%$ higher than the hand layup samples.

The inter-laminar bonding was also observed to be highest in VIP and lowest in hand layup process. The reason is the higher volume fraction of the reinforcement and a smaller number of voids in the VIP and after that vacuum bag samples as compared to hand layup.

By examining the macroscopic surface of the samples, it was found that the specimen was made in a vacuum-free manner, free from any bubbles and dries.

In terms of cost and time, it can be noted that hand layup is the cheapest and fastest process among these processes. The vacuum bag is then placed in the second position, and finally in the VIP, which is the slowest and costliest process among the three processes. Consequently, in each situation, it should choose the desired process according to the properties, time and price of the process

\section{ACKNOWLEDGMENTS}

The authors are very grateful to the editor and reviewers for their insightful and constructive comments and suggestions, which are very helpful in improving the quality of the article. This work was partially supported by the Center Composite Laboratory of Malek-Ashtar University of Technology (Tel: +98 21 22970274; Fax: +98 21 22936578).

\section{REFERENCES}

[1] George, L. (1982). An Overview of Composites. Chapter 14, New York, USA.

[2] Yang, J., Xiao, J., Zeng, J. (2011). An empirical model for resin viscosity during cure in vacuum infusion molding process. Applied Composite Materials, 19(3-4): 573-585. http://dx.doi.org/10.1007/s10443-011-9233-8

[3] Hammami, A., Gebart, B.R. (2000). Analysis of the vacuum infusion molding process. Polymer Composites, 21(1): 28-40. http://dx.doi.org/10.1002/pc.10162

[4] Feraboli, P., Masini, A. (2004). Development of carbon/epoxy structural components for a high performance vehicle. Composites Part B, 35: 323-330. http://dx.doi.org/10.1016/j.compositesb.2003.11.010

[5] Kedari, R., Farah, B. I., Hsiao, K.T. (2011). Effects of vacuum pressure, inlet pressure, and mold temperature on the void content, volume fraction of polyester/E-glass fiber composites manufactured with VARTM process. Journal of Composite Materials, 26(45): 2727-2742. http://dx.doi.org/10.1177/0021998311415442
[6] Wonderly, C., Grenestedt, J., Fernlund, G., Cepus, E. (2005). Comparison of mechanical properties of glass fiber/vinyl ester and carbon fiber/vinyl ester composites. Elsevier Journal in Engineering, 36(5): 417-42. http://dx.doi.org/10.1016/j.compositesb.2005.01.004

[7] Goren, C. (2008). Manufacturing of polymer matrix composites using vacuum assisted infusion molding. Archives of Material Science and Engineering, 34(2): 117-120.

[8] Khattab, A. (2005). Exploratory development of VARIM process for manufacturing high temperature polymer matrix composites. Ph.D. dissertation. University of Missouri, USA.

[9] Salah, S., Rawi, A. (2009). Fibers direction effect on tensile elasticity of epoxy composites using computer modeling. J. of University of Anbar for Pure Science, 3(3): 109-115.

[10] Kang, M.K., Lee, W.I., Hahn, H.T. (2001). Analysis of vacuum bag resin transfer molding process. Composites A, 32(11): 1553-1560. http://dx.doi.org/10.1016/S1359835X(01)00012-4

[11] Tzetzis, D., Hogg, P.J. (2008). Experimental and finite element analysis on the performance of vacuum-assisted resin infused single scarf repairs. Materials and Design, 29(2): 436-449. http://dx.doi.org/10.1016/j.matdes.2007.01.002

[12] Wisojodharmo, L.A., Roseno, S. (2012). The use of vacuum assisted resin infusion process on the manufacturing of wind blade composites. Journal of Materials Science and Engineering, 2(1): 74-78.

[13] Bhatnagar, A., Kumar, I.N.N. (2015). Vacuum infusion process for composite vessel construction. International Journal of Innovative Research and Development, 4(7): 1-7. https://dx.doi.org/10.1016/j.tig.2014.08.005

[14] Yuhazri, M., Phongsakorn, Y., Sihombing, H. (2010). A comparison process between vacuum infusion and hand lay-up method toward kenaf/polyster composites. International Journal of Basic \& Applied Sciences, 10(3): $1-4$.

[15] Khalili, S.M.R., Najafi, M., Eslami, R. (2013). Comparison of compressive properties between vacuum infusion and hand lay-up method toward balsa core sandwich composites. Journal of Mechanical Research and Application, 4(2): 33-40.

\section{NOMENCLATURE}

$\begin{array}{ll}\text { VIP } & \text { Vacuum Infusion Processing } \\ \text { HL } & \text { Hand Layup } \\ \text { VB } & \text { Vacuum Bag } \\ \text { GFRP } & \text { Glass Fiber Reinforced Plastic }\end{array}$

